\title{
The Causes of Susceptibility of the Elderly to COVID-19 Pneumonia Under the Natural State Based on a Behavioural Perspective: A Retrospective Study Taking ,the Early Onset of the Disease in Wuhan,China, as an Example
}

Qiang Niu ( $\nabla$ niuqiang@whu.edu.cn )

Wuhan University https://orcid.org/0000-0002-8016-4675

\author{
Yixiao Jiang \\ Wuhan University \\ Junbo Zhang \\ Wuhan University \\ Yikai Guo \\ Wuhan University \\ Zhiqiang Si \\ Wuhan University
}

\section{Research}

Keywords: elderly, behavioural patterns, susceptibility to infection, logistic regression, policy

Posted Date: June 25th, 2021

DOI: https://doi.org/10.21203/rs.3.rs-599096/v1

License: (c) (1) This work is licensed under a Creative Commons Attribution 4.0 International License. Read Full License 


\title{
1 The causes of susceptibility of the elderly to \\ 2 COVID-19 pneumonia under the natural state \\ 3 based on a behavioural perspective: a \\ 4 retrospective study taking the early onset of the \\ 5 disease in Wuhan, China, as an example
}

\author{
Qiang Niu ${ }^{1 *}$, Yixiao Jiang ${ }^{1}$, Junbo Zhang ${ }^{1}$, Yikai Guo ${ }^{1}$ and Zhiqiang $\mathrm{Si}^{1}$ \\ 1 School of Urban Design, Wuhan University, 299 Bayi Road, Wuchang District, Wuhan \\ 420072, China. \\ * Correspondence: niuqiang@whu.edu.cn; Tel.: +86-27-6877-3062(Q.N.)
}

\begin{abstract}
In the early epidemic of COVID-19 in Wuhan, the proportion of elderly patients over 60 years was significantly higher than that of other populations. However, with the implementation of strong social control measures, the proportion of which dropped rapidly to the same level as that of middle-aged patients (40-59), which indicated that the elders' social behavioural pattern may have some connections with the infection. A retrospective study was carried out to investigate the behavioural patterns of different age groups before the social distance control in Wuhan, to find out the relationship between them and the infection under the nature state, and furthermore, to put forward targeted suggestions to enhance the resistance of the elderly to public health emergencies. To carry out the research, social survey, one-way ANOVA and logistic regression models were utilized. The results showed that the elderly had more social activities, more offline shopping, more travels by semi-public transportation, and the factors below had significant impacts on the infection $(\mathrm{P}<0.05)$ : the level of indoor entertainment, the frequency of going to convenience stores or markets, the frequency of walking, and the level of protection. Besides, suggestions were proposed, including controlling the social distance of the elderly, developing senior-friendly shopping platforms, advocating tailored car travel, etc. This study could provide data and theoretical support for government's regulatory actions, enrich epidemiological theories of transmission routes based on behaviour, and improve the adaptability of the elderly to public health emergencies.
\end{abstract}

Keywords: elderly; behavioural patterns; susceptibility to infection; logistic regression; policy

\section{Background}

At the beginning of 2020, COVID-19 broke out in Wuhan, China, and then spread rapidly throughout China. At the initial stage of the outbreak, the government and the public did not fully understand about the coronavirus. Academician - - Nanshan Zhong first announced the existence of human-to-human transmission of COVID-19 on 20th Jan. Before that most Wuhan residents continued to purchase supplies for the Spring Festival. They underestimated its infectivity and didn't recognize it could be so severe. Behavioural patterns of most residents had not changed significantly so the epidemic developed rapidly. After academician Lanjuan $\mathrm{Li}$ put forward measures such as home quarantine, wearing masks, building container hospitals and locking down the city on 22nd Jan., which effectively cut off the spread channel of the virus, behaviours of Wuhan residents were changed significantly. At the end, the spread of the epidemic was successfully controlled. Until 8th Apr., 2020, when Wuhan city had been sealed off, there were 50,008 confirmed cases and 2,574 deaths in Wuhan with the resident 
population of 11.21 million, and there were 81,802 confirmed cases and 3,333 deaths in the whole country with the resident population of 1.4 billion [1].

Looking back at the history of the epidemic (Figure 1), the elderly over 60 years old were more susceptible than the younger population as for COVID-19. During the period from 1st Dec. 2019, the Lancet reported the first case of COVID-19 in Wuhan, to 9th Jan. 2020, the first death case of COVID-19, 51.8\% of COVID-19 patients were over 60 years old. With the introduction of a series of government control measures, until the closure of Wuhan on 23rd Jan., the proportion of the elderly people who were diagnosed with COVID-19 declined slightly, but it was still higher than other age groups in overall hospitalized patients. On 10th Apr., the elderly over 60 years old accounted for $42.4 \%$ of the total infected people in Wuhan. The infection proportion of young people under the age of 40 was $19.9 \%$, and that of middle-aged people aged 40 to 60 years old was $37.7 \%$ [2]. Progressively, the proportion of elderly patients was changing.

Since the end of January, the COVID-19 prevention and control headquarters in Wuhan had issued many notices, including 'Wuhan closed' on 23rd Jan, 'Suspension of net-booked cars and taxis' on 24th Jan, 'restricting the use of motor vehicles in the central city' on 31st Jan, which greatly reduced the unnecessary contact of the public and effectively slowed down the spread of COVID-19. In February, the government in Wuhan issued a notice: residential areas were managed in a closed way, and only one entrance was reserved in each community to restrict travel. Up to 8th Mar., the proportion of COVID-19 patients over 60 years old had dropped significantly to $35.4 \%$ of all patients, and people aged $40-59$ years old accounted for $33.9 \%$ [2]. It was the first time that the two age groups differed little.

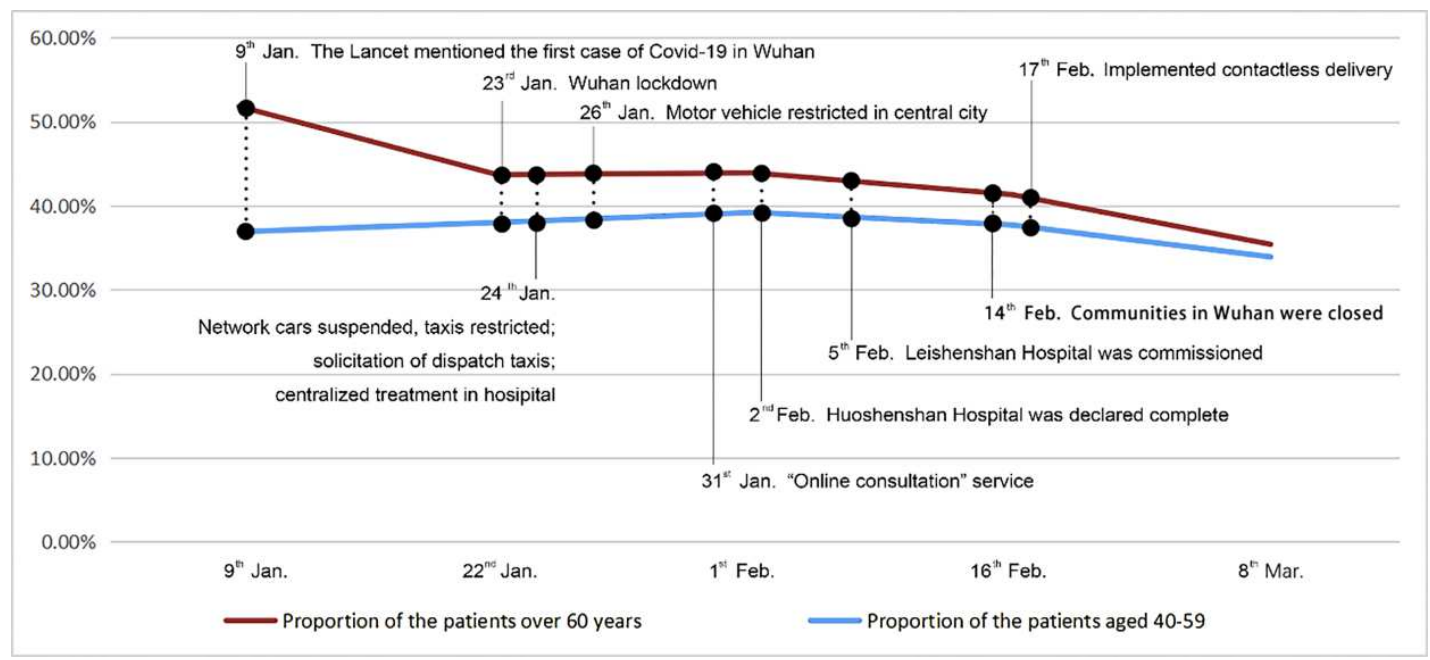

Figure 1. Policy implementation and age classes of COVID-19 patients.

The control measures in Wuhan had a significant effect and showed that the elderly were not more susceptible than other age groups after restricting social behaviour. A study also showed that, although the elderly was susceptible to infectious diseases [3], COVID-19 was common in all age groups.

By comparative analysis of the proportion of elderly patients before and after social control in Wuhan, we put forward the following hypothesis: behaviour of the elderly under the nature state was different from that of other age people, which was one of the main reasons why elders were more likely to suffer from the disease.

\subsection{Literature review}

Many scholars at home and abroad had paid close attention to the virus and invested considerable efforts in research, mainly focusing on the clinicopathological characteristics of 
patients with COVID-19 [4,5], the trend and prediction of COVID-19 infection and mortality in certain countries and regions [6,7], the configuration of urban medical system under the epidemic [8], and the measures to prevent and control the epidemic [9].

$\mathrm{Yu}$ Feng et al. proposed that COVID-19 virus could be transmitted through droplets produced by coughing and sneezing, or by contact with the virus [10]. In general, the main transmission routes of COVID-19 virus were close airborne droplets, contact with respiratory secretions of patients, and contact transmission [11]. Researches showed that droplet and contact transmission of the infectious virus were mainly reflected in people's daily lives through social interaction [10], shopping [12], transportation [13], hospital visits [14], and family life $[15,16]$. Yiqiang Liu pointed out that social interaction and mobility were the basis of COVID-19 virus transmission [17]. Zhang et al. suggested that transportation had become the main place of virus transmission in the epidemic because of its narrow space, dense population and close contact conditions [18].

From the perspective of behavioural patterns, Junxiong Li et al. found that during the epidemic, most young and middle-aged shoppers shifted their spending from offline to online, while the older consumers, with less level of informatization, could only risk infection by buying food in supermarkets, convenience store or market complexes [19]. For the elderly aged 60-75, life satisfaction was closely related to face-to-face social activities [20]. Food markets were more popular among the elderly, because they could provide lower prices, more varieties and more opportunities to interact with others [21]. Older people relied more on non-motorized transportation than younger people, and there is a stronger relationship between their mobility patterns and the distribution of leisure service facilities [22]. Shan Hu pointed out that the elderly had a higher rate of infection and mortality due to their worse physical resistance, more narrow social patterns, comorbidities, and looking down on the epidemic [23].

To sum up, existing research results showed that COVID-19 was mainly transmitted through airborne droplets and contact in people's daily activities such as socializing, shopping and transportation, etc. The elderly were more likely to be infected due to their poor health and negative attitude towards the epidemic. There was still a lack of research on the relationship between the high infection rate of the elderly and their daily behaviours, and few scholars had conducted in-depth research on the specific behaviours that may lead to higher infection rate in social interaction, shopping and transportation.

The paper attempts to analyze the link between different behavioural patterns under nature state and diseases by investigating behaviour habits of different age people. Specifically, the questionnaire was designed in terms of shopping, social life, travel, and protective measures, etc. The data were collected through the Internet and telephone. To determine the significance of behavioural differences between the elderly and the middle-aged, we used a one-way ANOVA. The logistic regression model was introduced to explore the factors that could have had the greatest influence on the disease state under various behaviours and to prove the correlation between the disease state and behavioural patterns. Finally, considering the effectiveness of policies implemented in Wuhan during the epidemic, some suggestions and policy supplements were put forward to improve the behaviour of the elderly. This article is expected to provide data and theoretical support for the government's regulatory actions, enrich epidemiological theories of transmission routes based on behaviour, and improve the adaptability of the elderly to public health emergencies in daily state.

\section{Data and Method}

\subsection{Research Data}

The first outbreak of COVID-19 epidemic was in Wuhan, Hubei Province, which was the epicenter of outbreak development in China. As of 8th Apr., 2020, when Wuhan was unsealed, the total number of infected people in Wuhan had been 50,340, which means the rate of 
infection in Wuhan was $4.49 \%$, accounting for $73.88 \%$ of the number of infected people in Hubei Province and $61.54 \%$ in China [1]. At the same time, Wuhan was located in the middle reaches of the Yangtze River with a resident population of 11.212 million in 2019 of which $21.43 \%$ were over 60 years old [24]. Consequently, it is typical to study the COVID-19 infection among the elderly in Wuhan.

In order to collect data on behaviours of the elderly under their natural state to exclude the effect of epidemic control, the samples of patients interviewed in this paper were limited to those diagnosed before 6th Feb., 2020. When Wuhan closed on 23rd Jan., Wuhan residents realized the seriousness of the epidemic, and their living behaviours were then constrained accordingly. Due to the 14-day average incubation period of the virus before the onset of the disease, it could be roughly assumed that people who were diagnosed before 6th Feb. were infected before the city was closed. At this time, their living behaviours were basically unaffected by the epidemic which could be considered under nature state.

During April-June, 126 eligible patients' information was obtained through Chinese microblogging site Weibo, with the keywords 'COVID-19 patients called for help'. The patients had been diagnosed without getting a hospital bed in time, so they sought help on Weibo, which could lead to greater awareness and faster access to help. Patients who seek help will post their certificate of diagnosis, personal information (including name, age, address, etc.), and date of diagnosis on the Internet. In this survey, phone numbers of the patients were collected manually and randomly on Weibo. For non-illness residents of Wuhan, we conducted the survey by distributing a questionnaire on the Internet. The main methods of investigation included making telephone conversations with COVID-19 patients to conduct semi-structured interviews. The survey included basic information (gender, age, physical condition), whether or not the respondent was infected with COVID-19 ( the time of illness and suspected possible causes). Based on the literature review, the survey was conducted from the following patterns of behaviour: social behaviours (frequency, duration, number of people, protective measures), shopping behaviours (frequency, congestion, protective measures), travel frequency and Internet usage (frequency, access to information).

\subsection{Research Methods}

The results of the survey were used to calculate the means or proportions of variables such as frequency, duration of social interaction, number of contacts, shopping congestion, and protective measures of social, shopping and transportation for the elderly and middle-aged groups. Differences between the two groups were measured to determine the behavioural characteristics of older adults that differed from those of younger adults. One-way ANOVA was used to statistically analyze the significantly different characteristic variables between two groups. Logistic regression analysis method was introduced to demonstrate which behaviours had significant effects on the infection rate.

\section{Results}

\subsection{Statistical Characteristics of the Sample}

In terms of the patients, a total of 35 questionnaires were obtained, and 34 of them were valid. To conduct a comparative study, online surveys were conducted for people who were not infected the virus as the control group, 44 questionnaires were collected and 38 of them were valid. The survey was difficult and required a lot of time and effort. We went through as many surveys as possible and ended up with a valid sample of 72 with an efficiency rate of $91.1 \%$, which is more than the 30 needed to do a correlation analysis, so we could get a reliable result. The ratio of patients to non-patients is 1:1.12. There are 18 elderly patients (age $\geq 60$ ), 16 young and middle-aged patients $(18<$ age $<60), 15$ elderly non-patients, and 23 young and middle-aged non-patients (Table. 1). 
Table 1. Description of overall characteristics of the study samples(n=72).

\begin{tabular}{ccc}
\hline Characteristics & $\mathbf{n}$ & $\mathbf{\%}$ \\
\hline Gender & & \\
Male & 37 & 51.39 \\
Female & 35 & 48.61 \\
Age & & \\
$18-29$ & 16 & 22.22 \\
$30-44$ & 9 & 12.5 \\
$45-59$ & 14 & 19.44 \\
$\geq 60$ & 33 & 45.83 \\
\hline
\end{tabular}

176

A statistical analysis of residents' behavioural pattern between two populations obtained from the questionnaire was conducted. The results are shown in Table 2. There are many significant differences $(\mathrm{Sig}<0.05)$. Older adults exercise outdoors, play indoors, chat occasionally, and shop at convenience stores and food markets more frequently than younger adults. They are also less likely to use the Internet for online socializing and shopping. The duration that older adults spend outdoors exercising was longer than that of young and middle-aged adults. Protective measures between older adults and younger adults are significantly different. Older adults are less likely than younger adults to take precautions when shopping and socializing. In terms of travel, older adults walk more often, but take cars less often than younger adults. We used the investigators' self-rated health status scores to compare the differences in physical condition between the two groups. Both groups differ significantly in terms of their physical condition and use of online electronic devices.

Table 2. Statistics on the behavioural patterns of elderly and young and middle-aged.

\begin{tabular}{|c|c|c|c|c|c|c|c|}
\hline & & $\begin{array}{c}\text { Group 1: } \\
\text { The } \\
\text { elderly }\end{array}$ & $\begin{array}{l}\text { Group } \\
\text { 1: S.D. }\end{array}$ & $\begin{array}{c}\text { Group 2: } \\
\text { The young } \\
\text { and middle- } \\
\text { aged }\end{array}$ & $\begin{array}{l}\text { Group } \\
\text { 2: S.D. }\end{array}$ & $\begin{array}{l}\text { ANOVA } \\
\text { between } \\
\text { groups: F }\end{array}$ & $\begin{array}{c}\text { ANOVA } \\
\text { between } \\
\text { groups: Sig. }\end{array}$ \\
\hline \multirow{7}{*}{$\begin{array}{l}\text { Frequency } \\
\text { of social } \\
\text { activity } \\
\text { (weekly) }\end{array}$} & $\begin{array}{l}\text { Outdoor } \\
\text { exercise }^{* * *}\end{array}$ & 2.76 & 2.50 & 0.80 & 1.43 & 17.57 & 0.00 \\
\hline & $\begin{array}{l}\text { Indoor } \\
\text { entertainment ** }\end{array}$ & 2.12 & 2.63 & 0.84 & 1.50 & 6.85 & 0.01 \\
\hline & Dinner parties & 0.38 & 0.81 & 0.55 & 0.95 & 0.67 & 0.41 \\
\hline & Performance & 0.14 & 0.44 & 0.28 & 0.72 & 0.93 & 0.34 \\
\hline & Casual chat ${ }^{* * *}$ & 3.45 & 2.48 & 1.10 & 1.38 & 26.19 & 0.00 \\
\hline & Linking game ${ }^{* *}$ & 0.17 & 0.96 & 1.21 & 2.34 & 5.77 & 0.02 \\
\hline & Webchat*** & 0.70 & 1.30 & 2.42 & 2.49 & 12.96 & 0.00 \\
\hline \multirow{5}{*}{$\begin{array}{l}\text { Duration of } \\
\text { social } \\
\text { (minutes } \\
\text { ) }\end{array}$} & $\begin{array}{l}\text { Outdoor } \\
\text { exercise }^{* * *}\end{array}$ & 32.42 & 26.34 & 13.75 & 21.98 & 10.91 & 0.00 \\
\hline & $\begin{array}{c}\text { Indoor } \\
\text { entertainment }\end{array}$ & 27.58 & 29.16 & 17.75 & 24.70 & 2.43 & 0.12 \\
\hline & Dinner parties & 10.00 & 22.08 & 19.63 & 27.56 & 2.63 & 0.11 \\
\hline & Performance & 6.36 & 18.00 & 8.75 & 20.25 & 0.28 & 0.60 \\
\hline & Casual chat & 5.76 & 3.34 & 7.25 & 15.52 & 0.29 & 0.59 \\
\hline
\end{tabular}




\begin{tabular}{|c|c|c|c|c|c|c|c|}
\hline \multirow{5}{*}{$\begin{array}{c}\text { Number of } \\
\text { social }\end{array}$} & $\begin{array}{l}\text { Outdoor } \\
\text { exercise }^{* * *}\end{array}$ & 2.59 & 3.19 & 0.98 & 1.44 & 8.23 & 0.00 \\
\hline & $\begin{array}{c}\text { Indoor } \\
\text { entertainment }\end{array}$ & 2.20 & 2.74 & 1.61 & 2.60 & 0.87 & 0.35 \\
\hline & Dinner parties & 0.91 & 2.18 & 1.46 & 2.25 & 1.12 & 0.29 \\
\hline & Performance & 1.82 & 5.84 & 2.14 & 5.63 & 0.06 & 0.81 \\
\hline & Casual chat & 1.41 & 1.03 & 1.2 & 1.75 & 0.37 & 0.55 \\
\hline \multirow{4}{*}{$\begin{array}{c}\text { Social } \\
\text { precautions } \\
(\%)^{* * *}\end{array}$} & $\begin{array}{l}\text { Class III } \\
\text { precaution }\end{array}$ & 3.20 & -- & 30.00 & -- & \multirow{4}{*}{29.26} & \multirow{4}{*}{0.00} \\
\hline & $\begin{array}{l}\text { Class II } \\
\text { precaution }\end{array}$ & 6.06 & -- & 25.00 & -- & & \\
\hline & $\begin{array}{c}\text { Class I } \\
\text { precaution }\end{array}$ & 36.19 & -- & 27.50 & -- & & \\
\hline & None & 54.55 & -- & 17.50 & -- & & \\
\hline \multirow{6}{*}{$\begin{array}{c}\text { Frequency } \\
\text { of shopping } \\
\text { (weekly) }\end{array}$} & $\begin{array}{c}\text { Convenience } \\
\text { stores }^{* *}\end{array}$ & 1.68 & 1.63 & 2.7 & 2.16 & 5.24 & 0.02 \\
\hline & Supermarkets & 0.92 & 1.19 & 1.24 & 1.42 & 1.01 & 0.32 \\
\hline & Food markets* & 2.52 & 2.71 & 1.53 & 2.25 & 2.91 & 0.09 \\
\hline & Street stall & 0.77 & 1.38 & 0.68 & 1.43 & 0.09 & 0.77 \\
\hline & Takeaways*** & 0 & 0 & 1.39 & 2.02 & 15.52 & 0.00 \\
\hline & $\begin{array}{c}\text { Online } \\
\text { shopping*** }\end{array}$ & 0.11 & 0.61 & 2.35 & 2.08 & 35.72 & 0.00 \\
\hline \multirow{4}{*}{$\begin{array}{c}\text { Shopping } \\
\text { crowed } \\
\text { level }\end{array}$} & $\begin{array}{c}\text { Convenience } \\
\text { store }\end{array}$ & 2.58 & 1.06 & 2.25 & 1.21 & 1.46 & 0.23 \\
\hline & Supermarket & 2.15 & 1.44 & 2.35 & 1.35 & 0.37 & 0.55 \\
\hline & Food market & 2.79 & 1.47 & 2.23 & 1.37 & 2.85 & 0.10 \\
\hline & Street stall** & 1.15 & 0.44 & 1.60 & 0.93 & 6.48 & 0.01 \\
\hline \multirow{4}{*}{$\begin{array}{l}\text { Shopping } \\
\text { precautions } \\
(\%)^{* * *}\end{array}$} & $\begin{array}{l}\text { Class III } \\
\text { precaution }\end{array}$ & 6.06 & -- & 32.50 & -- & \multirow{4}{*}{10.83} & \multirow{4}{*}{0.00} \\
\hline & $\begin{array}{l}\text { Class II } \\
\text { precaution }\end{array}$ & 18.18 & -- & 25.00 & -- & & \\
\hline & $\begin{array}{c}\text { Class I } \\
\text { precaution }\end{array}$ & 30.30 & -- & 20.00 & -- & & \\
\hline & None & 45.45 & -- & 22.50 & -- & & \\
\hline \multirow{6}{*}{$\begin{array}{l}\text { Frequency } \\
\text { of travel } \\
\text { (weekly) }\end{array}$} & Walk*** & 5.35 & 2.34 & 2.81 & 2.54 & 19.33 & 0.00 \\
\hline & Bike & 0.85 & 1.82 & 0.91 & 1.49 & 0.03 & 0.87 \\
\hline & Bus & 1.79 & 1.63 & 1.38 & 1.87 & 0.99 & 0.32 \\
\hline & Underground* & 0.52 & 1.28 & 1.14 & 1.56 & 3.38 & 0.07 \\
\hline & Car** & 0.23 & 1.31 & 1.13 & 2.01 & 4.89 & 0.03 \\
\hline & Taxi** & 0.00 & 0.00 & 0.41 & 1.10 & 4.65 & 0.03 \\
\hline
\end{tabular}




\begin{tabular}{|c|c|c|c|c|c|c|c|}
\hline & 1 & 3.03 & -- & 0.00 & -- & \multirow{5}{*}{9.11} & \multirow{5}{*}{0.00} \\
\hline Physical & 2 & 21.21 & -- & 7.50 & -- & & \\
\hline Health & 3 & 36.37 & -- & 22.50 & -- & & \\
\hline \multirow[t]{3}{*}{ Score ${ }^{* * *}$} & 4 & 30.30 & -- & 45.00 & -- & & \\
\hline & 5 & 9.09 & -- & 25.00 & -- & & \\
\hline & Never & 42.43 & -- & 5.00 & -- & \multirow{4}{*}{74.66} & \multirow{4}{*}{0.00} \\
\hline \multirow{3}{*}{$\begin{array}{l}\text { Usage of } \\
\text { electronic } \\
\text { equipment } \\
(\%)\end{array}$} & $\begin{array}{l}\text { 1-2 times per } \\
\text { week }\end{array}$ & 36.36 & -- & 5.00 & -- & & \\
\hline & $\begin{array}{c}\text { 3-4 times per } \\
\text { week }\end{array}$ & 9.09 & -- & 2.50 & -- & & \\
\hline & Everyday & 12.12 & -- & 87.50 & -- & & \\
\hline
\end{tabular}

Note: S.D. is Standard Deviation; ANOVA is Analysis of Variance; F is F-criterion; Sig. is Significance.

$$
{ }^{*} \text { Sig }<0.1 ;{ }^{* *} \operatorname{Sig}<0.05 ; * * * \operatorname{Sig}<0.01
$$

\subsection{Social behaviour}

The social behaviours such as outdoor exercise, indoor entertainment, gathering meals, watching performances, and occasional chat would be called offline social, while interact online would be called online social. People's physical contact behaviour was an important factor in the spread of the virus in this epidemic. On the contrary, the online behaviour reduced the occurrence of large-scale infection, provided the potential to resist epidemic continuously, and reduced the risk of infection.

\subsubsection{Differences in social styles}

From the characteristics of the elderly sample, the overall social behaviours of 'frequent offline socialization and lack of online socialization' could be seen distinctly. For offline social interaction, only $30 \%$ of people used the Internet to socialize. According to the characteristics of the young and middle-aged, the proportion of online social contact increased significantly, and it showed a flexible alternation between online and offline social interaction generally.

By comparing the choice of social behaviours, it could be seen that older people were more likely to choose offline contact socialization than online non-contact socialization. Young and middle-aged people could use electronic equipment to socialize, so that they could make up for the absence of offline socialization through online socialization.

Based on the comparison of social interaction patterns, we further analyzed the specific social behaviours of each age group, including social frequency, duration, number of people, and protection measures. The Figure 2 shows that the older people socialized more frequently than young and middle-aged people, and the proportion of contact socialization among the elderly is much higher.

Specifically, the average weekly frequency of social contact (including outdoor exercise, indoor entertainment, performance appreciation, dinner party, and casual chat) of the elderly was higher than the young and middle-aged. The elderly mainly relied on offline socialization to meet their daily social needs. 


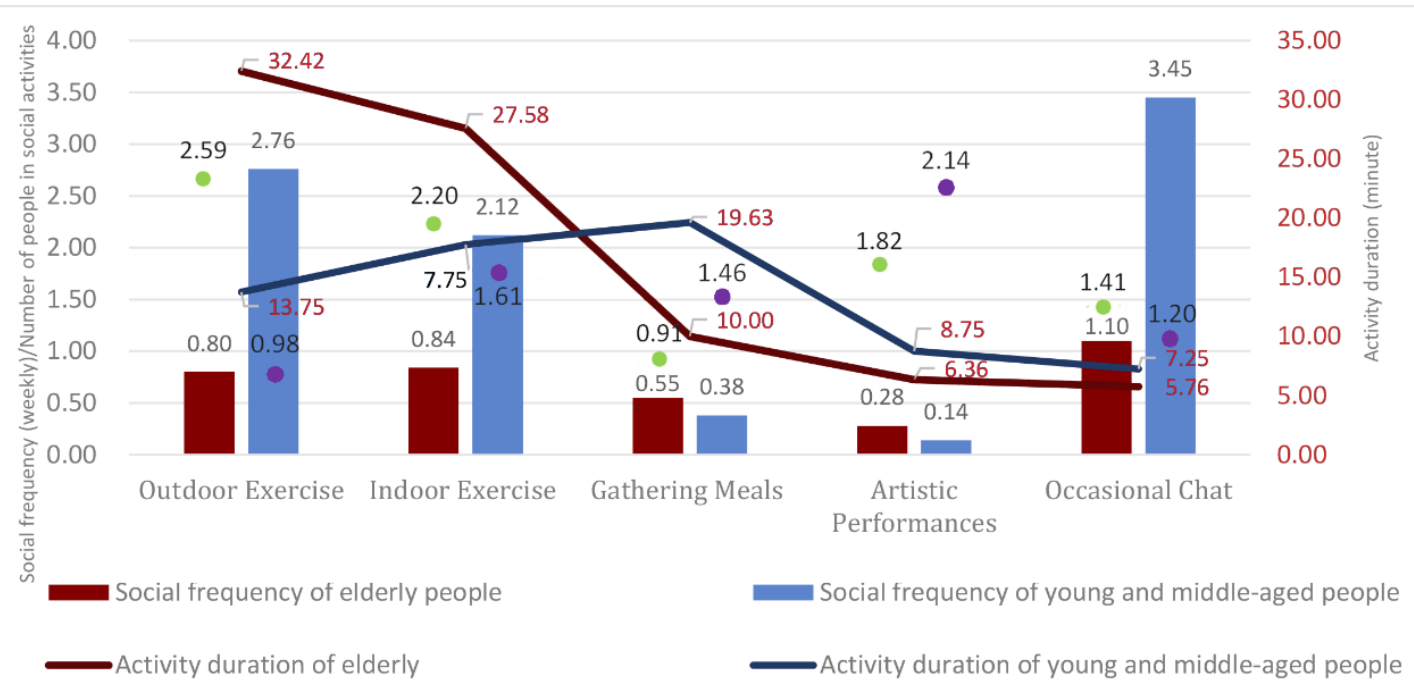

- Number of participants in social activities of the elderly

- Number of participants in social activities of the middle-aged

Figure 2. Social frequency, duration, and the participant number.

Table 3. Logistic regression results of social behaviours.

\begin{tabular}{cccc}
\hline Variable name & Coefficient & Significance & OR \\
\hline Frequency of outdoor exercise & 0.199 & 0.296 & 1.221 \\
Frequency of indoor entertainment *** & 1.041 & $\mathbf{0 . 0 0 2}$ & 0.353 \\
Frequency of gathering meals & -0.329 & 0.237 & 1.275 \\
Frequency of watching performances * & -0.484 & 0.092 & 0.569 \\
Frequency of occasional chat & 0.391 & 0.169 & 1.662 \\
Frequency of online games & -0.001 & 0.997 & 0.999 \\
Frequency of online chat * & -0.439 & 0.092 & 0.645 \\
Duration of outdoor exercise & 0.291 & 0.173 & 1.337 \\
Duration of indoor entertainment ** & 0.472 & $\mathbf{0 . 0 1 7}$ & 0.624 \\
Duration of gathering meals & 0.263 & 0.161 & 1.300 \\
Duration of artistic performances & -0.071 & 0.264 & 0.931 \\
Duration of occasional chat & 0.240 & 0.345 & 1.271 \\
Number of people for outdoor exercise * & 0.447 & 0.062 & 1.563 \\
Number of people for indoor entertainment *** & 0.716 & $\mathbf{0 . 0 0 1}$ & 0.489
\end{tabular}




\subsection{Shopping behaviour}

People's physical contact shopping behaviour was an important factor in the spread of the virus in this epidemic. The shopping behaviours in food markets, supermarkets, food shops, and street stalls would be called offline shopping, while goods purchased by online platforms would be called online shopping, such as Taobao, JD.com (online shopping platform) and Meituan (online ordering platform).

The density of the virus in space was the key factor in determining its transmission rate, and the efficiency of virus transmission was lower in open and ventilated outdoor sites than indoors. Therefore, shopping in a closed indoor environment became an important factor for COVID-19 virus. Crowded and narrow shopping space created favorable conditions for virus spreading through droplets and contact. The more frequently people go shopping in this environment, the more likely they would be infected. Protective measures after shopping such as wearing masks and gloves, sterilizing clothes, could effectively reduce the possibility of personal contact with virus.

\subsubsection{Differences in shopping behaviour}

As Figure 3 shows, older adults made more physical purchases per week, and sick older adults made more than non-sick older adults. Moreover, physical purchases accounted for a higher proportion of total shopping frequency in both comparison trials.

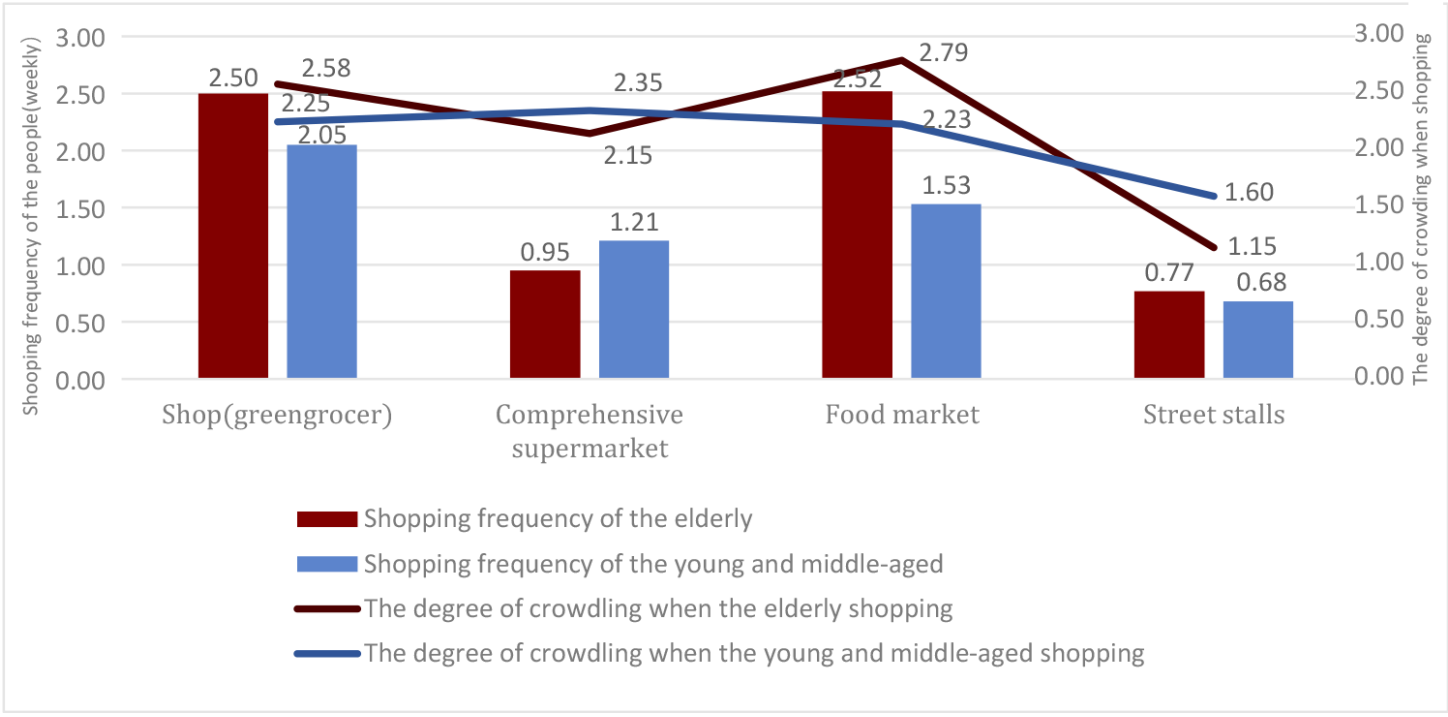

Figure 3. Physical Shopping Frequency and Crowding Degree.

In the comparison of offline shopping behaviours between elderly and young and middleaged people, we found that the elderly went to food markets most frequently. The elderly shopped more often and longer in vegetable markets and stores than young and middle-aged people, where the probability of infection was higher in physical stores. The sick elderly shopped more often and longer in food markets than the non-sick elderly.45.5\% of the elderly had no protection, and only $6.1 \%$ of the elderly protect themselves effectively and correctly including wearing masks and gloves, sterilizing clothes after shopping and so on. Among the 
younger adults, there were $32.5 \%$ with correct protection. The survey results show that the general protection level of the elderly was low, and their awareness of protection is poor.

\subsubsection{Logistic regression results of shopping behaviour}

The result of logistic regression analysis shows that the model Omnibus Test result was 0.001 , and the overall percentage of prediction was $76.4 \%$, with a high confidence level. Table 4 shows the regression results.

The frequency of shopping at convenience stores, food markets, the degree of congestion in supermarkets, and the level of protection negatively correlated to illness is significant. With the increase of shopping frequency of convenience stores, food markets, the degree of congestion in supermarkets, the ratio of the probability of getting sick to not getting sick increases by $2.426 \%, 1.77 \%, 2.852 \%$. The ratio of the probability of getting sick to the probability of not getting sick decreases by $0.359 \%$ with the improvement of protection level.

Table 4. Logistic regression results of shopping behaviour.

\begin{tabular}{cccc}
\hline Variable name & Coefficient & Significance & OR \\
\hline Shopping frequency at convenience stores ** & 0.886 & $\mathbf{0 . 0 1 2}$ & 2.426 \\
Shopping frequency at general supermarkets * & -0.707 & 0.079 & 0.493 \\
Shopping frequency at food markets** & 0.571 & $\mathbf{0 . 0 2 5}$ & 1.770 \\
Shopping frequency at street stalls & -0.328 & 0.303 & 0.720 \\
Shopping frequency on the Internet & -0.117 & 0.631 & 0.889 \\
Frequency of takeout & 0.115 & 0.662 & 1.122 \\
Congestion of convenience stores & -0.657 & 0.228 & 0.518 \\
Congestion of general supermarket $* * *$ & 1.038 & $\mathbf{0 . 0 0 6}$ & 2.825 \\
Congestion of the vegetable market & -0.218 & 0.617 & 0.804 \\
Congestion of street stalls & 0.127 & 0.865 & 1.136 \\
Protection level $* * *$ & -1.025 & $\mathbf{0 . 0 0 7}$ & 0.359 \\
\hline
\end{tabular}

Note: ${ }^{*} \mathrm{P}<0.1 ;{ }^{* *} \mathrm{P}<0.05 ;{ }^{* *} \mathrm{P}<0.01$.

According to the above analysis, the frequency of visiting convenience stores, food stores and markets, the degree of congestion in supermarkets, and the level of protection have a greater impact on shopping behaviour.

\subsection{Travel behaviour}

According to the transmission characteristics of coronavirus, with the increase of people's exposure, the probability of infection of COVID-19 increased correspondingly. In this process of analyzing modes of transportation, six common modes of transportation including walking, cycling, bus, Underground, taxi, and driving have been counted. To facilitate statistical analysis, the modes of transportation were classified according to the different exposure risks, and the possibility of infection was ranked from high to low, which were divided into three categories: public transportation, semi-public transportation and private transportation. Because of the high population density and closed space, buses and Undergrounds were classified as public transport. Walking and taking taxis were classified as semi-public transportation because of the strong contingency and relatively open space. Biking and driving were classified as private transportation because of the clear destinations, low population density and completely private space.

\subsubsection{Differences in travel behaviour}

Comparing the results of the elderly and the young and middle-aged showed by Figure 4, the elderly took public transport more frequently, while the frequency of public transportation used by the elderly was almost the same as that of young and middle-aged people. Besides, the 
elderly made fewer trips on private transport. In the comparison between sick and non-sick elderly people, sick elderly people traveled more frequently by semi-public transportation and rarely chose private transportation.

The elderly were more likely to use semi-public transport and less likely to use private transport, because they lacked driving skills and preferred to walk leisurely. Compared with private transportation, semi-public transportation was a direct cause of the increased risk of the disease, because of the high degree of exposure, which also showed that the choice of transportation did have an impact on the disease risk.

Figure 4. Frequency of each transport modes for people with and without illness.

\subsubsection{Logistic regression results of travel behaviour}

Table 5 shows that the model Omnibus Test result is 0.018 and the overall percentage of prediction is $69.4 \%$, which shows that the reliability of research results was high. The results of the regression analysis are as follows.

Table 5. Logistic regression results of travel behaviour.

\begin{tabular}{cccc}
\hline VARIABLE NAME & COEFFICIENT & SIGNIFICANCE & or \\
\hline FREQUENCY OF WALKING ${ }^{* *}$ & 0.281 & $\mathbf{0 . 0 1 3}$ & 1.325 \\
FREQUENCY OF CYCLING & -0.278 & 0.155 & 0.758 \\
FREQUENCY OF TAKING BUSES & 0.21 & 0.341 & 1.233 \\
FREQUENCY OF TAKING THE UNDERGROUND & 0.009 & 0.971 & 1.009 \\
FREQUENCY OF DRIVING & -0.018 & 0.925 & 0.982 \\
FREQUENCY OF TAKING TAXI & -0.26 & 0.538 & 0.771 \\
\hline
\end{tabular}

Note: ${ }^{*} \mathrm{P}<0.1 ;{ }^{* *} \mathrm{P}<0.05 ;{ }^{* * *} \mathrm{P}<0.01$.

According to the data in the table, the walking mode is highly significant. For each increase in the number of walking, the ratio of sick to non-sick increased by $1.325 \%$. And this is consistent with the expectation that walking pattern is incidental and often intertwined with social behaviours. Therefore, walking has a great influence on traffic behaviour.

\section{Discussion}

According to the results of this survey, it can be learned that the reason why elderly people are susceptible to COVID-19 under the natural state is related to the characteristics of their daily behavioural patterns.

1. Elderly people have more frequent face-to-face social interaction including outdoor exercise, indoor entertainment and casual chatting. In addition, the frequency of indoor recreation and casual chatting have a significant effect on the infection of the disease. Therefore, the elderly is more susceptible to COVID-19. The main modes of transmission of COVID-19 are 
contact transmission and close droplet transmission. Physical contact and close talk in the process of offline social interaction increase the risk of illness.

2. Elderly people have more frequent offline shopping including shopping at convenience stores and food markets. In the process of shopping, consumers stay in indoor environments with poor air circulation and high population density. According to the study, the frequency of shopping at convenience stores, supermarkets, and food markets, the crowdedness of supermarkets, and the precautions taken while shopping had a significant effect on the infection of the disease. Products are displayed in a public manner, which often touched and selected by multiple consumers. Thus, the virus can spread rapidly using these commodities as carriers, which provides advantageous conditions for the spread of novel coronavirus.

3. Elderly people have more walking. For reasons of exercise and cost-saving, walking was one of the most important travel modes for the elderly. Different from other modes of travel, walking was not only a complete process of reaching a destination, but also usually accompanied by occasional social behaviours, such as bumping into acquaintances while walking, which increases the risk of COVID-19 among the elderly.

These behaviours are important factors in the susceptibility of the elderly to COVID-19 because they are consistent with the core of novel coronavirus' transmission - contact, which results in a high risk of viral infection in the elderly. And as humans' activities are often complex and integrated, the social behaviours are often mutually influential and interactive. This investigation is demonstrated that the above behaviours are indeed important causes of susceptibility to COVID-19 in the elderly.

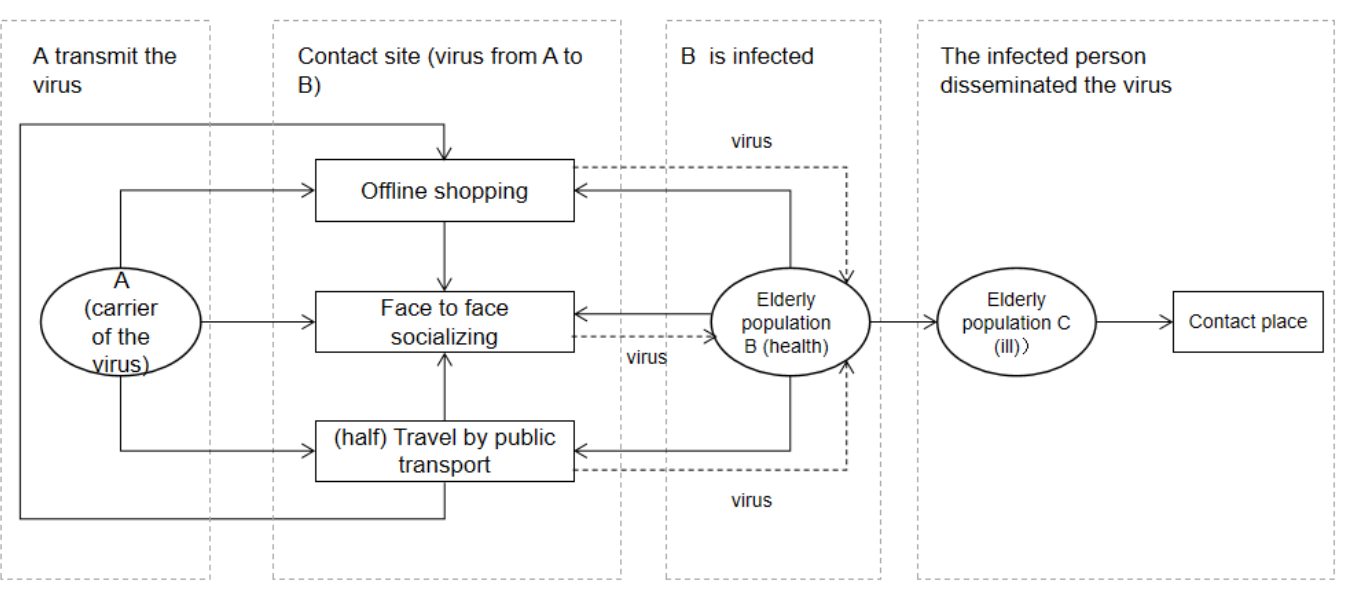

Figure 5. Diagram of the relationship between virus transmission and behaviour.

As we investigate further, the factors that contribute to the increased susceptibility of older people to COVID-19 include not only direct factors, but also several indirect factors (Figure 6).

1. Low level of informatization in the elderly. In this information age, the network has been integrated with people's lives, and information technology such as cashless payment and online shopping has greatly improved the efficiency of our lives. However, the learning cost of technology makes the elderly do not have the ability and willingness to learn new technology. As a consequence, they still prefer the traditional model to socialize and go shopping in daily life, which causes a higher risk of exposure during the epidemic. Moreover, due to the increasing proportion of online taxis in China, more and more cabs are moving to online services [24]. Hailing a taxi has become difficult for the elderly who do not use smartphones skillfully.

2. Elderly people have negative attitudes towards the epidemic. Wearing a mask is an excellent means of blocking the spread of the virus, and the decision to wear a mask depends on the government's macro-control and the individual's will. Due to the negative attitude of 
the elderly towards the epidemic, their mask-wearing rate and willingness to wear masks is lower, which has greatly reduced their ability to resist the virus.

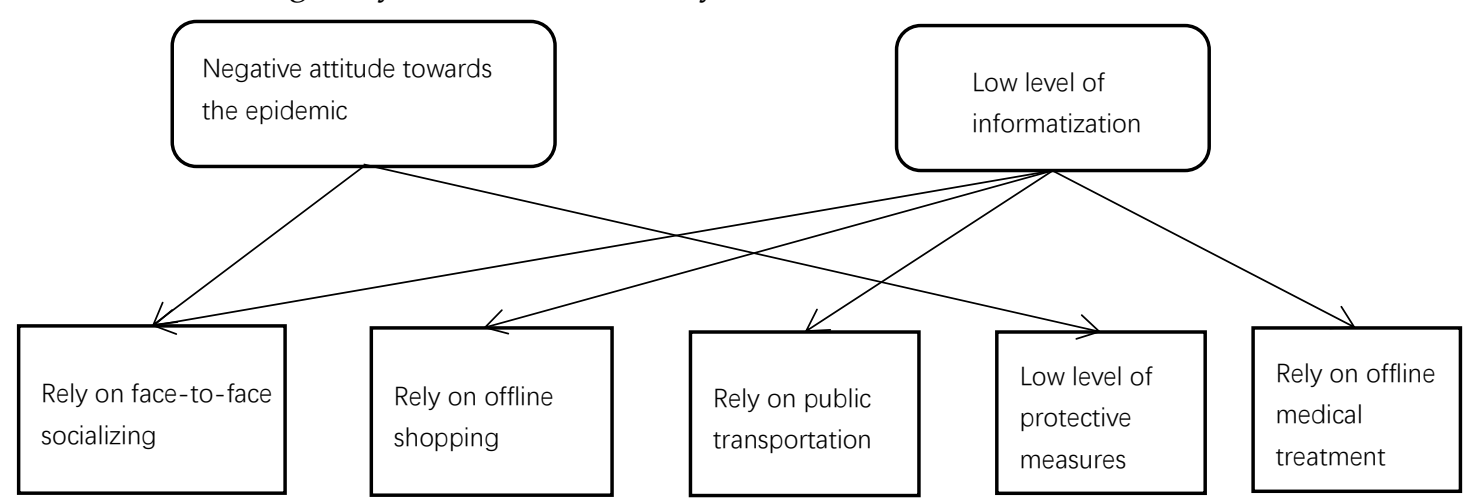

Figure 6. Influence of Indirect Factors on the elderly's daily Behaviour.

Some of these daily behaviours that make the elderly vulnerable to COVID-19 are real problems that need improvement, such as improving the resistance of the elderly to the unknown development of rapidly spreading respiratory infections. Behavioural patterns of elderly can be adapted with proper guidance to make them more capable of combining online and offline. Older people in their natural state can also reduce their chances of contracting infectious diseases in the future.

Because the investigation was conducted during the epidemic, the research methods have some limitations. Most of the patients were sensitive to epidemic-related experiences, so it was difficult to research on a large scale, which limited the sample size. Data were collected by semi-structured interviews which were easily influenced by the interviewees' own comprehension and subjective factors, so there may be respondent errors. The study conducts regression analyses on three aspects which have most significant impact early in the development of the epidemic: socialization, shopping, and transportation, but lacks a consideration of other activities such as health seeking behaviours and work behaviours. As a consequence, the accuracy and generalizability of the research results can be further confirmed. We believe that the general rules of the conclusions are clear.

\section{Conclusion}

The results show that the elderly have more social activities, more offline shopping, more travels by walking, and the factors below have significant impacts on the infection $(\mathrm{P}<0.05)$ : the level of indoor entertainment, the frequency of going to convenience stores or food markets, the frequency of walking, and the level of protection. During the epidemic, some policies of the Wuhan government have resisted the spread of the virus to a large extent, such as the closure of access routes to Wuhan, the closure of communities and high-traffic facilities and the suspension of public transport. They also controlled the spread of the virus by reducing unnecessary shopping, social and travel behaviours. The proportion of sick elderly people was relatively high among all patients at the beginning of the epidemic, but the closure of the city of Wuhan led to a substantial reduction in the proportion of elderly people who became ill. Other policies also had a dampening effect on the illness of elderly people. In the policy context of strict epidemic prevention, most of the policies focus on prohibiting and restricting the behaviour of the residents. The elderly is at a loss when it comes to sudden prohibitive policies. The promulgation and implementation of 'age-friendly' policies should be optimized and adjusted in the 'post epidemic period '.

In the aspect of social interaction of the elderly, their online social interaction ability in daily life should be enhanced. Moreover, we should mobilize the community or other relevant staff to supervise and control the social distance of the crowd with reasonable means. Social 
networking platforms for the elderly should be developed and promoted reasonably. The level of information technology among the elderly should be raised.

In the aspect of shopping of the elderly, in order to reduce the frequency of offline shopping during the epidemic, the online shopping ability of the elderly should be improved. The unified purchase and distribution of daily necessities should be done well during the epidemic period. During the non-epidemic period, a shopping platform for the elderly should be developed. The government should enhance community $\mathrm{O} 2 \mathrm{O}$ construction, which makes online and offline services to complement each other.

In the aspect of transportation of the elderly, the ability of the elderly to travel by netbooked car should be enhanced on the premise of ensuring the safety of the elderly. Public transport should also be strictly controlled and uniformly deployed during the epidemic period.

The maintenance of social responsibility and mental health of the elderly should be concerned. Negative attitudes such as blind self-confidence and indifference to the epidemic among some elderly people have led to low levels of self-protection. In the epidemic, the government should not only mandate to wear masks, but also disseminate correct epidemic prevention measures in an easy-to-understand manner. During non-epidemic periods, the community should strengthen the social responsibility of the elderly through targeted education and collective activities.

\section{Declarations}

Ethics approval and consent to participate: Not applicable. The researchers in the study explained the purpose of the survey to the respondents during the randomization process and all of the respondents informed consent. The anonymous survey included basic information (gender, age, physical condition), whether or not the respondent was infected with COVID-19 (the time of illness and suspected possible causes), social behaviors (frequency, duration, number of people, protective measures), shopping behaviors (frequency, congestion, protective measures), travel frequency and Internet usage (frequency, access to information). The respondents' basic information was strictly protected. The study did not have any adverse effects on the respondents. Therefore, ethical approval is not required for this study by Office of Scientific Research, School of Urban Design at Wuhan University.

Consent for publication : Not applicable.

Availability of data and materials: The datasets used and/or analysed during the current study are available from the corresponding author on reasonable request.

Competing interests : We declare that we have no competing interests.

Funding: This research was funded by National Natural Science Foundation of China, grant number (51778503, 51308422).

Authors' contributions: Q.N. led the work and was responsible for the conceptualization of the project, formulation of the methodology, writing the original draft, edited and improved the manuscript and interpreting the results. Y.J. conducted statistical analysis, edited and improved the manuscript. J.Z. did the formal analysis and writing the original draft. Y.G. did the investigation and visualized the figure. Z.S. visualized the figure and writing the original draft. All authors read and approved the final manuscript.

Acknowledgements: We thank Dr. Yang Yu for his great help in translation.

\section{References}

1. Update on the Novel Coronavirus Pneumonia Outbreak as of $8^{\text {th }}$ Apr on 24:00. Available online: http://www.gov.cn/xinwen/2020-04/09/content 5500435.htm .Accessed on 9 $9^{\text {th }}$ Apr.,2020.

2. Pan, A; Liu, L; Wang, C; et al. Association of Public Health Interventions With the Epidemiology of the COVID-19 Outbreak in Wuhan, China. JAMA. 2020;323(19):1915-1923. 
doi:10.1001/jama.2020.6130.

3. Pan, F. The elderly are a key population group to prevent neo-coronary pneumonia--Prof. Zhong Nanshan, Academician of Chinese Academy of Engineering and Head of the High-Level Expert Group of National Health Commission. China Medical Herald,2020, 17(06):1-3.

4. Tu, H.L.; Tu, S.; Gao, S.Q.; Shao, A.W.; Sheng, J.F. Current epidemiological and clinical features of COVID-19; a global perspective from China. Journal of Infection,2020, 81(1):1-9.

5. Gan, H.; Zhang, Y.; Yuan, M.; Wu, X.Y.; Liu, Z.R.; Liu, M.; Wu, J.B.; Xu, S.J.; Gong, L.; Xu, H.L; Tao, F.B. Epidemiological characterization of 1052 cases of aggregated novel coronavirus pneumonia. Chinese Journal of Epidemiology, 2020(05):E027.

6. Bai, Y.X.; Nie, X.; Wen, C.X. Epidemic Prediction of 2019-nCoV in Hubei Province and Comparison with SARS in Guangdong Province. https://papers.ssrn.com/sol3/results.cfm .Accessed on 4 Feb, 2020.

7. Li, Q.; M. Med., Xu H.G.; Ph.D., Peng W.; Ph.D., Xiao Y.W.; M.P.H., Lei Z.; M.Med., Ye Q.T.; Ph.D., Ren, R.Q.; M.Med., Kathy S.M.Leung; Ph.D., Eric H.Y. Lau, Ph.D., Jessica Y. Wong, Ph.D., Xue S.X.; Ph.D., Ni J.X.; M.Med., et al. Early Transmission Dynamics in Wuhan, China, of Novel Coronavirus - Infected Pneumonia. New England Journal of Medicine, 2020, 382(13): 1199-1207.

8. Requia, W.J.; Kondo, E.K.; Adams, M.D.; Gold, D.R.; Struchiner, C.J. Risk of the Brazilian health care system over 5572 municipalities to exceed health care capacity due to the 2019 novel coronavirus (COVID-19). Science of the Total Environment,2020,730:139144.

9. Wang J.; Feng, H.T.; Zhang, S.; Ni, Z.W.; Ni, L.M.; Chen, Y.; Zhuo, L.X.; Zhong, Z.F.; Qu, T.T. SARSCoV-2 RNA detection of hospital isolation wards hygiene monitoring during the Coronavirus Disease 2019 outbreak in a Chinese hospital. International Journal of Infectious Diseases, 2020,94:103-106.

10. Feng, Y.; Thierry, M.; Ted, S.; Yi, H. Influence of wind and relative humidity on the social distancing effectiveness to prevent COVID-19 airborne transmission: A numerical study. Journal of Aerosol Science, 2020, 147:105585.

11. Sheng H.X.; Wu L.; Wu C.L. Modeling Analysis and Prediction on NCP Epidemic Transmission. Journal of System Simulation, 2020, 5: 759-766.

12. Shan, H.R.; Lin, H.; Yuan, M.; Huang, Y.P. An empirical analysis of the control effect of offline entertainment and shopping trips in Wuhan during the new crown epidemic. Economic Geography,2020,04:96-102.

13. Armando, C.; Luigi D.F.; Maria M. How Mobility Habits Influenced the Spread of the COVID-19 Epidemic: Results from the Italian Case Study. Science of the Total Environment, 2020, 741, 140489.

14. Biribawa, C.; Atuhairwe J.A.; Bulage L.; Okethwangu D.O.; Kwesiga B.; Ario A.R.; Zhu B.P. Measles outbreak amplified in a pediatric ward: Lyantonde District, Uganda, August 2017. BMC Infectious Diseases, 2020,20(1): 398.

15. Ye, F.; Xu, S.C.; Rong, Z.H.; Xu, R.H.; Liu, X.W.; Deng, P.F.; Liu, H.; Xu, X.J. Delivery of infection from asymptomatic carriers of COVID-19 in a familial cluster. International Journal of Infectious Diseases, 2020,94: 133-138.

16. Wan, R; Mao, Z.Q.; He, L.Y.; Hu, Y.C.; Chen, W. Evidence from Two Cases of Asymptomatic Infection with SARS-CoV-2: Are 14 days of isolation sufficient? International Journal of Infectious Diseases, 2020, 95:174-175.

17. Liu, Y.Q. Epidemic transforms social, community and mobility to recreate a new ecosystem of social connections. People's Tribune,2020,S1:22-25.

18. Zhang ,Y.; Tian, W.L.; Wu, Z.G.; Chen Z.W.; Wang, J. Transmission Mechanism of COVID-19 along Traffic Lines Based on Improved SEIR Model. Journal of Transportation Engineering, 2020(7):1-10.

19. Li, J.X.; Alan, G.; Hallsworth, J.; Andres, C.S. Changing Grocery Shopping Behaviours Among Chinese Consumers At The Outset Of The COVID-19 Outbreak. Tijdschrift Voor Economische En Sociale Geografie,2020,111(3):574-583.

20. Chen, S.Y.; Fu, Y.C. Leisure Participation and Enjoyment Among the Elderly: Individual Characteristics and Sociability.Educational Gerontology,2008,34(10):871-889.

21. Feng, J.X. The influence of built environment on travel behaviour of the elderly in urban China. Transportation Research Part D: Transport and Environment,2017,52:619-633. 
22. $\mathrm{Hu}, \mathrm{S}$. Research on the impact of the neocon epidemic on the elderly and the response to it. Heilongjaing Science, 2020,11(06):141-143.

23. Julie, Y.C. Thrown under the bus and outrunning it! The logic of Didi and taxi drivers' labour and activism in the on-demand economy. New Media\& Society, 2018, 20(8):2691-2711.

24. Wuhan Statistical Yearbook 2018. http://tjj.wuhan.gov.cn/tjfw/tjnj/202004/P020200426461240969401.pdf .Accessed on 15 ${ }^{\text {th }}$ May,2020. 